\title{
Comparative Evaluation of Three Different Techniques for Open Reduction and Fixation of Anterior MandibulComparative Evaluation of Three Different Techniques for Open Reduction and Original Fixation of Anterior Mandibular Fracturesar Fractures Article
}

\author{
Mohammad Abdelhamied Shuman and Bahaa El-Din A. Tawfik \\ Department of Oral and Maxillofacial Surgery, Faculty of Dentistry, \\ Al-Azhar University (Boys), Cairo, Egypt
}

\begin{abstract}
Aim of the study: To compare the safety and efficacy of three different fixation techniques for anterior mandibular fractures, namely two lag screws, 3D miniplate, and two miniplates.

Methods: In randomized, controlled, trial, we enrolled patients with anterior mandibular fractures. Patients were randomly allocated to one of the following fixation techniques: group (1): two lag screws, group (2): 3D miniplate and group (3): two miniplates. All patients were followed-up for six months.

Results: Thirty patients were included. The miniplates group had statistically significant longer time for hardware fixation than patients in the other two groups $(p<0.00)$. The frequencies of satisfactory occlusion were numerically higher in lag screw and $3 \mathrm{D}$ plates groups than the miniplates group $(p>0.05)$. The overall rate of moderate postoperative complications was significantly higher in miniplates group than lag screw and 3D plate groups at the $1^{\text {st }}$ postoperative week $(p=0.01)$. On the $1^{\text {st }}$ postoperative months, the overall rate of mild complications was significantly higher in miniplates group than lag screw and 3D plate groups at the $1^{\text {st }}$ postoperative week and month $(p<0.001)$.

Conclusion: Fixation with lag screws and 3D plates lead to less frequency and severity of postoperative complications than fixation with miniplates for anterior mandibular fractures.
\end{abstract}

Key Words: Anterior Mandibular Fractures, Lag screws, Miniplates, 3D plates.

Received: 16 August 2020, Accepted: 15 September 2020.

Corresponding Author: Mohammad Abdelhamied, Department of Oral and Maxillofacial Surgery, Faculty of Dentistry, Al-Azhar University (Boys), Cairo, Egypt, Tel.: +20224718796, Mobile: +201005227310, E-mail: showmadrill@gmail. com.

\section{INTRODUCTION}

The incidence of oral and maxillofacial traumas dramatically increased in the past few decades. Mandibular fracture occurs more commonly than any other facial fracture, outnumbering zygomatic and maxillary fractures by a proportion of 6 to 2 to 1 respectively ${ }^{[1,2]}$. This common injury results mainly from personal assaults, road traffic accidents, heavy falls, and sports traumas ${ }^{[2]}$. Likewise, cumulative analyses revealed that anterior mandibular fractures represent over $17 \%$ of all mandibular fractures ${ }^{[3,4]}$.

Ideally, the ultimate goal of any fracture management is to restore the original anatomical structure and function earlier as possible with the most limited adverse events and discomfort ${ }^{[5,6]}$. With that in mind, the management procedures of mandibular fractures have evolved substantially in recent decades ${ }^{[7]}$. Previously, fractures were operated through closed techniques, including maxillomandibular fixation, external fixation and splints ${ }^{[7,8]}$. In the modern era: the use of rigid internal fixation enabled the fast regain of function and shortened the convalescence period ${ }^{[8]}$.
The plate fixation system has gone through successive modifications, from the unfavorable lower border application, and the distracted buccal surface fixation, to the open reduction and internal fixation utilizing plates ${ }^{[9]}$. This latter procedure has become a widely recommended practice while in contrast to orthopedic surgery, lag screws become indispensable in maxillofacial osteosynthesis ${ }^{[10]}$. For lag screw not only immobilize the fractured parts but also provide a continuous compression on the fracture region $^{[10,11]}$.

Meanwhile, the curvature of the anterior mandible, the thickness of the bony cortices, and the absence of anatomical hazards below the apices of the teeth make the anterior mandible suitable for different plate techniques including screws and miniplates ${ }^{[12]}$. The comparative efficacy among these delicate procedures is still questionable ${ }^{[12]}$. Considering this, we performed this randomized controlled clinical trial (RCT) to compare the safety and efficacy of fracture fixation techniques among three groups, received two lag screws, 3D miniplate and two miniplates. 


\section{MATERIALS AND METHODS}

The present manuscript was prepared in concordance with the recommendations of CONSORT statement ${ }^{[13]}$.

\section{Study Design and Patients:}

In this RCTs, we enrolled adult patients with anterior mandibular fractures and seeking treatment from the outpatient dental clinics of Sayed Galal Hospital. Patients were deemed eligible if they had radiologically confirmed, recent, anterior mandibular fractures and accepted to undergo surgery under general anesthesia. We excluded patients with comminuted fracture, edentulous patient, soft tissue loss, previously treated fracture with mal-united bony segments and patients who were not willing to comeback for follow-up visits. Before surgery, all patients signed the informed consents and the study's protocol was approved from the ethics committee of Sayed Galal Hospital.

Patients were randomly allocated using MedCalc (C) version 18.2.1 in 1:1:1 ration to one of the following groups: group (1): Fixation with two lag screws (Figure 1), group (2): Fixation with 3D miniplate (Figure 2) and group (3): Fixation with two miniplates (Figure 3). All patients informed about the details of the procedure and sign written consent.

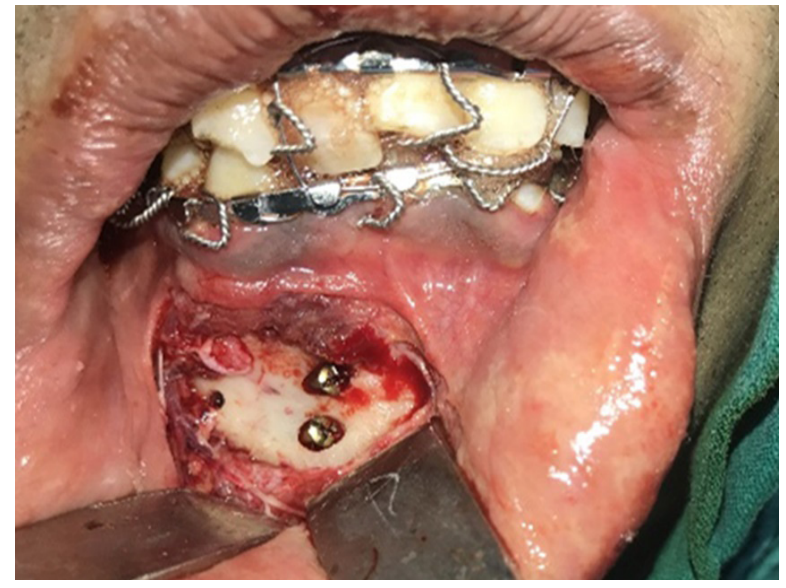

Figure 1: Lag screw fixation.

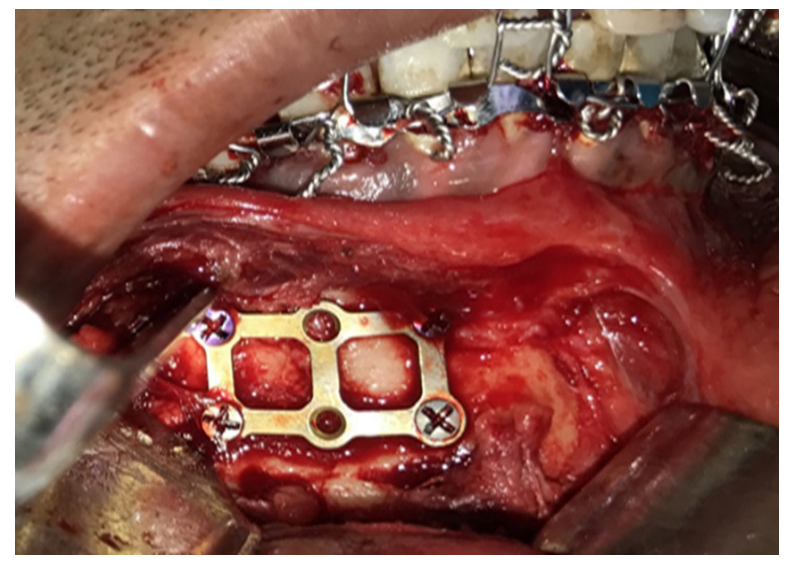

Figure 2: Three D plate fixation.

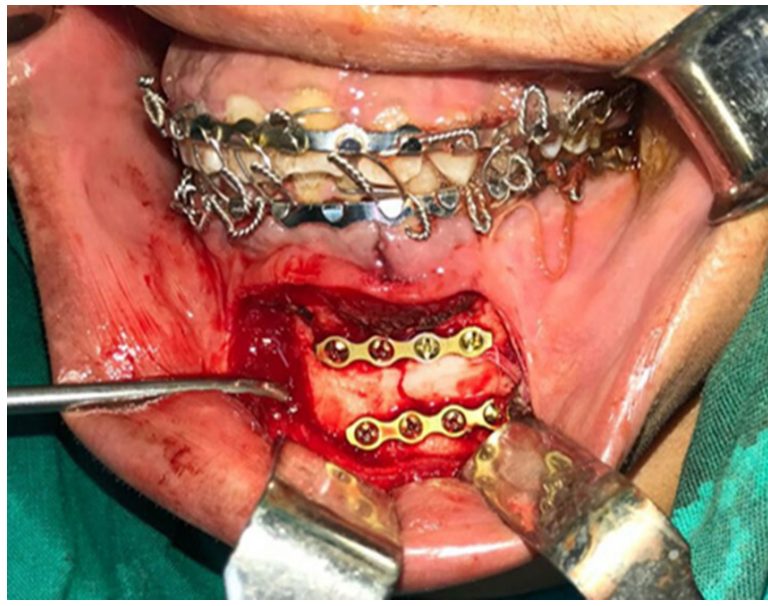

Figure 3: Two miniplates fixation.

\section{Follow-up:}

All patients were followed clinically and radiographically at the first postoperative day and at one week, one month, three months, and six months postoperatively. The evaluation parameters included, intraoperative fixation time, pre and postoperative occlusion, fracture stability and radiographic score. The radiological score was ranged from 1 to 3 in which score 1 denotes need for revision surgery due to improper alignment and poor occlusion, score 2 denotes slight malalignment of the fixed parts with satisfactory occlusion and score 3 denotes precise reduction in the fracture site. Also, the postoperative complications, which included pain, edema, paresthesia, infection, dehiscence, malunion/ un-union and hardware exposure were evaluated.

\section{Study's outcomes:}

The primary outcome in the present study was the difference in postoperative occlusion, fracture stability, and radiographic score between different fixation methods. The secondary outcome was to assess the postoperative complications of the different fixation methods.

\section{Statistical Analysis:}

The statistical analyses were employed using SPSS software using SPSS version 22.0 for Windows. The mean \pm standard deviation $( \pm$ SD) or median with interquartile range (IQR) were used to describe numerical variables according to the normality of the data. Frequencies with percentages were applied to present categorical variables. The association between quantitative variables was examined using unpaired Student's t-test for normally distributed data or Mann-Whitney Rank Sum test for non-normally distributed data. The Chi-square test was implemented to identify the level of significance for categorical variables. The level of significance was set at a probability critical value ( $p$-value) lower than 0.05 . 


\section{RESULTS}

In this study, a total of 30 patients (10 patients per group) with anterior mandibular fractures were included. The majority of patients were males amongst the studied groups $(p=0.74)$. We noted no statistically significant difference between studied groups regarding the age $(p=0.85)$ and causes of fractures $(p=0.81)$. On the other hand, patients in miniplates group had statistically significant longer time for hardware fixation (20.1 [16.3 - 22.3] minutes) than patients in leg screw (15.9 [12.1 - 19.1] minutes) and 3D plates (13.7 [10.6 - 16.9] minutes) groups, with $p$-value of $<0.001$ (Table 1).

As regard the degree of occlusion, all patients had deranged occlusion preoperatively. On the $1^{\text {st }}$ postoperative day, week and month, the frequencies of satisfactory occlusion were numerically higher in lag screw and 3D plates groups than the miniplates group, however, it did not reach the level of statistical significance $(p>0.05)$. All patients had satisfactory occlusion at the end of $6^{\text {th }}$ month of the follow-up (Table 2). Preoperatively, all patients had unstable fractures, which turned into stable fractures throughout the study's period until the end of $6^{\text {th }}$ month of the follow-up. In terms of radiological findings, all patients had a radiological score of 3 at the preoperative period. Postoperatively, all patients had a radiological score of 1 until the end of $6^{\text {th }}$ month of the follow-up.

The overall rate of moderate postoperative complications was significantly higher in miniplates group than lag screw and 3D plate groups at the $1^{\text {st }}$ postoperative week (70 \% versus $10 \%$ versus $10 \%$, respectively, $p=0.01)$. On the 1 st postoperative months, the overall rate of mild complications was significantly higher in miniplates group than lag screw and $3 \mathrm{D}$ plate groups at the $1^{\text {st }}$ postoperative week $(p<0.001)$. Likewise, the incidence of mild complications was significantly higher in miniplates group than lag screw and 3D plate groups at the $1^{\text {st }}$ postoperative month $(p<0.001)$. No procedurerelated complications were reproted at the $3^{\text {rd }}$ and $6^{\text {th }}$ month of follow-up (Figure 4). However, the incidence of each complication was comparable across the studied groups (Table 3). We recorded no cases of hardware exposure or mal-union throughout the study's period.

Table 1: Pre and Intraoperative Characteristics of the studied groups:

\begin{tabular}{|c|c|c|c|c|c|}
\hline \multicolumn{2}{|c|}{ Variables } & \multirow{2}{*}{$\begin{array}{c}\begin{array}{c}\text { Lag screw } \\
(\mathrm{n}=10)\end{array} \\
34.5(18-55)\end{array}$} & \multirow{2}{*}{$\begin{array}{c}\begin{array}{c}3 \mathrm{D} \text { plate } \\
(\mathrm{n}=10)\end{array} \\
29(18-49)\end{array}$} & \multirow{2}{*}{$\begin{array}{c}\begin{array}{c}\text { Miniplate } \\
(n=10)\end{array} \\
34.5(18-53)\end{array}$} & \multirow{2}{*}{$\frac{P \text {-value }}{0.85}$} \\
\hline Age & Median (Range) & & & & \\
\hline Male & Freq. $(\%)$ & $8(80 \%)$ & $9(90 \%)$ & $9(90 \%)$ & 0.74 \\
\hline \multirow{4}{*}{ Fracture cause } & Fall & $1(10 \%)$ & $1(10 \%)$ & $1(10 \%)$ & \multirow{4}{*}{0.81} \\
\hline & Fight & 0 & $1(10 \%)$ & $1(10 \%)$ & \\
\hline & RTA & $8(80 \%)$ & $8(80 \%)$ & $8(80 \%)$ & \\
\hline & Sport & $1(10 \%)$ & 0 & 0 & \\
\hline $\begin{array}{l}\text { Hardwire fixati } \\
\text { time } \\
\text { (minutes) }\end{array}$ & Median (Range) & $15.9(12.1-19.1)$ & $13.7(10.6-16.9)$ & $20.1(16.3-22.3)$ & 0.001 \\
\hline
\end{tabular}

Table 2: Distribution of degree of occlusion of the studied groups:

\begin{tabular}{|c|c|c|c|c|c|}
\hline & Variables & $\begin{array}{l}\text { Lag screw } \\
\qquad(\mathrm{n}=10)\end{array}$ & $\begin{array}{l}\text { 3D plate } \\
(n=10)\end{array}$ & $\begin{array}{l}\text { Miniplate } \\
(\mathrm{n}=10)\end{array}$ & $P$-value \\
\hline Preoperative & Deranged & $10(100 \%)$ & $10(100 \%)$ & $10(100 \%)$ & --- \\
\hline \multirow[t]{3}{*}{$1^{\text {st }} \mathrm{PO}$ day } & Deranged & 0 & $1(10 \%)$ & $1(10 \%)$ & \\
\hline & Mild Deranged & $2(20 \%)$ & $2(20 \%)$ & $3(30 \%)$ & 0.84 \\
\hline & Satisfactory & $8(80 \%)$ & $7(70 \%)$ & $6(60 \%)$ & \\
\hline \multirow[t]{3}{*}{$1^{\text {st }}$ week } & Deranged & 0 & 0 & $1(10 \%)$ & 0.33 \\
\hline & Mild Deranged & $1(10 \%)$ & $1(10 \%)$ & $4(40 \%)$ & \\
\hline & Satisfactory & $9(90 \%)$ & $9(90 \%)$ & $5(50 \%)$ & \\
\hline \multirow[t]{3}{*}{$1^{\text {st }}$ month } & Deranged & 0 & 0 & 0 & \\
\hline & Mild Deranged & 0 & $1(10 \%)$ & $3(30 \%)$ & 0.28 \\
\hline & Satisfactory & $10(100 \%)$ & $9(90 \%)$ & $7(70 \%)$ & \\
\hline \multirow[t]{3}{*}{$3^{\text {rd }}$ months } & Deranged & 0 & 0 & 0 & \\
\hline & Mild Deranged & 0 & 0 & $1(10 \%)$ & 0.99 \\
\hline & Satisfactory & $10(100 \%)$ & $10(100 \%)$ & $9(90 \%)$ & \\
\hline $6^{\text {th }}$ months & Satisfactory & $10(100 \%)$ & $10(100 \%)$ & $10(100 \%)$ & --- \\
\hline
\end{tabular}


Table 3: Distribution of postoperative complications of the studied groups:

\begin{tabular}{|c|c|c|c|c|c|}
\hline & Variables & $\begin{array}{l}\text { Lag screw } \\
\quad(\mathrm{n}=10)\end{array}$ & $\begin{array}{l}\text { 3D plate } \\
(\mathrm{n}=10)\end{array}$ & $\begin{array}{c}\text { Miniplate } \\
(\mathrm{n}=10)\end{array}$ & $P$-value \\
\hline \multirow[t]{4}{*}{$1^{\text {st }}$ PO day } & Edema & $10(100 \%)$ & $10(100 \%)$ & $10(100 \%)$ & --- \\
\hline & Paresthesia & $3(30 \%)$ & $2(20 \%)$ & $4(40 \%)$ & 0.87 \\
\hline & Wound infection & $3(30 \%)$ & $2(20 \%)$ & $3(30 \%)$ & 0.84 \\
\hline & Wound dehiscence & 0 & 0 & 0 & --- \\
\hline \multirow[t]{4}{*}{$1^{\text {st }}$ week } & Edema & $3(30 \%)$ & $2(20 \%)$ & $7(70 \%)$ & 0.051 \\
\hline & Paresthesia & $2(20 \%)$ & $1(10 \%)$ & $4(40 \%)$ & 0.43 \\
\hline & Wound infection & 0 & 0 & 0 & --- \\
\hline & Wound dehiscence & $2(20 \%)$ & 0 & $2(20 \%)$ & 0.51 \\
\hline \multirow[t]{4}{*}{$1^{\text {st }}$ month } & Edema & 0 & 0 & 0 & --- \\
\hline & Paresthesia & 0 & 0 & $2(20 \%)$ & 0.31 \\
\hline & Wound infection & 0 & 0 & 0 & --- \\
\hline & Wound dehiscence & 0 & 0 & 0 & --- \\
\hline \multirow[t]{4}{*}{$3^{\text {rd }}$ months } & Edema & 0 & 0 & 0 & --- \\
\hline & Paresthesia & 0 & 0 & 0 & --- \\
\hline & Wound infection & 0 & 0 & 0 & --- \\
\hline & Wound dehiscence & 0 & 0 & 0 & --- \\
\hline \multirow[t]{4}{*}{$6^{\text {th }}$ months } & Edema & 0 & 0 & 0 & --- \\
\hline & Paresthesia & 0 & 0 & 0 & --- \\
\hline & Wound infection & 0 & 0 & 0 & -- \\
\hline & Wound dehiscence & 0 & 0 & 0 & --- \\
\hline
\end{tabular}

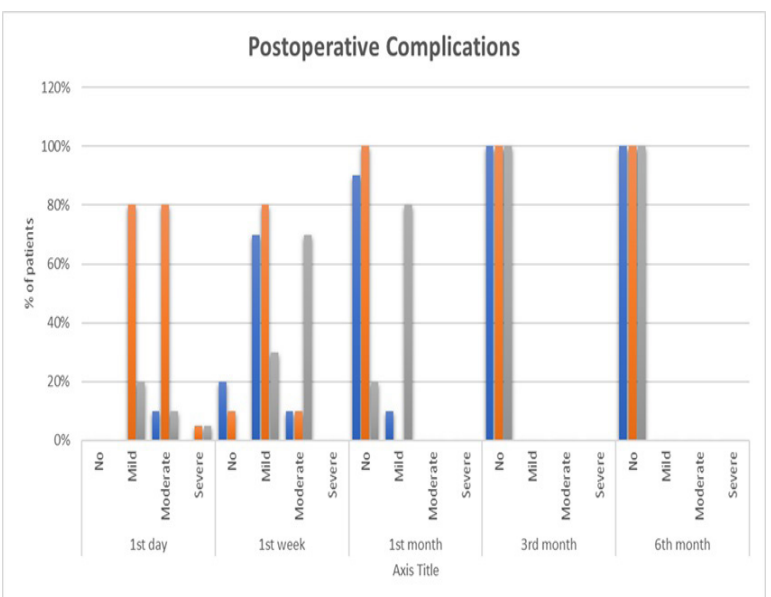

แLag Screws \30 miniplate $\mathbb{4}$ Two miniplates

Figure 4: Incidence of postoperative complications. 


\section{DISCUSSION}

Although proper fixation is essential to provide adequate stability for the anterior mandibular factures, there is no consensus regarding the optimal fixation technique for this special type of fracture. In the present RCT, we observed that the lag screw and $3 \mathrm{D}$ plates fixation techniques led to shorter hardware fixation time than miniplates technique. In addition, lag screw and 3D plates fixation techniques had the advantage of lower rates of postoperative complications, in the first month after the operation, compared to miniplates technique. Lag screws and $3 \mathrm{D}$ plates led to earlier restoration of occlusion function than the miniplates group; despite that the difference did not reach the level of statistical significance. However, the three fixation techniques were comparable regarding stability and radiological outcomes.

Open reduction and internal fixation is a widelyaccepted modality for surgical treatment of anterior mandibular fractures, which have the advantages of early functional recovery and high rate of stable fractures ${ }^{[8]}$. Lag screw is a cheap fixation tool that allows proper stability and compression of the fractures, previous reports indicated that lag screws can be easily placed in the setting of anterior mandibular fractures, leading to short surgical time and, hence, lower risks of postoperative morbidities ${ }^{[14]}$. The use of miniplates, as a fixation method for anterior mandibular fractures, has increased in many centers owing to their small size and the feasibility of intraoral approaches ${ }^{[15]}$. The efficacy of miniplates in providing proper stability and early clinical recovery is controversial ${ }^{[16,17]}$. This controversy mainly stems from limited ability of miniplates to provide 3D stability of the fractures. Thus, the introduction of 3D plates in the setting of mandibular fracture has the potential of better stability than the conventional plates, a growing evidence supported the efficacy and reliability of 3D plates fixation of anterior mandibular fractures ${ }^{[18]}$. In the present study, we demonstrated that the lag screws and 3D plates led to earlier restoration of occlusion function than the miniplates group; despite that the difference did not reach the level of statistical significance due to small sample size. However, the three fixation techniques were comparable regarding stability and radiological outcomes. In a recent two reports by Elhussein et al. ${ }^{[19]}$, and El Nakeeb et al..$^{[20] \text {, }}$ the rates of satisfactory clinical and radiological outcomes were comparable between miniplates and lag screw and 3D plates, respectively. Nonetheless, other published reports showed significantly better improvement in early clinical and radiological outcomes following lag screws, compared to miniplates ${ }^{[21,22]}$. Likewise, in a recent systematic review, the lag screws and 3D plates were superior to miniplates in terms of early clinical outcomes ${ }^{[8]}$. Thus, it is imperative to conduct a multinational study with rigors design to assess the impact of different fixation methods on clinical and radiological outcomes.
Operative time can significantly influence the rate of postoperative morbidities, in addition to its impact on overall operative $\operatorname{cost}^{[23]}$. Thus, it is important to choose the fixation method that provides the shortest operative time. In the present study, we found that patients in miniplates group had statistically significant longer time for hardware fixation than patients in leg screw and 3D plates groups. This was in agreement with Wusiman et al. ${ }^{[8]}$, systematic review that showed shorter operative time following leg screw and 3D plates than miniplates. Other reports showed similar findings ${ }^{[21,24]}$.

As regard to complication rates, we found that lag screw and 3D plates fixation techniques had the advantage of lower rates of postoperative complications, in the first month after the operation, compared to miniplates technique. However, the incidence of each complication was comparable across the studied groups, mainly due to small sample size. Likewise, lag screw and 3D plates fixation exhibited lower rates of postoperative complications than miniplates in Wusiman et al. ${ }^{[8]}$. Similar findings were reproted by Bhatnagar et al. ${ }^{[25]}$, and Agnihotri et al. ${ }^{[26]}$. According to Elhussein et al.$^{[19]}$, both lag screws and 3D plates are associated with better intra-fracture stability, less manipulation, and less bone drilling; which can result in lower rates of postoperative edema and pain.

To our knowledge, there are few studies compared the three fixation methods for anterior mandibular fractures. However, the study showed some limitations: 1) All patients recruited from one center only, therefore, these results may not be generalized to all patients: 2) this was a comparative study and there was no long follow-up, so we cannot document the long-term outcomes and 3) The number of patients included in this study was limited by availability.

\section{CONCLUSION}

In conclusion, both lag screws and 3D plates are feasible and safe fixation methods for anterior mandibular fractures. Both techniques appear to be superior to miniplates in terms of early restoration of mandibular function; however, all three techniques were comparable regarding fracture stability and radiological findings. The lag screws and $3 \mathrm{D}$ plates had the advantage of shorter fixation time than the miniplates as well. In addition, the lag screw and 3D plates result in lower incidence of early postoperative complications than the miniplates. It is important that further multinational studies to be conducted to find and confirm the superiority of lag screws and $3 \mathrm{D}$ plates over the conventional plates.

\section{CONFLICT OF INTEREST}

The authors declare no conflict of interest. 


\section{REFERENCES}

1. Manodh, P., Prabhu Shankar, D., Pradeep, D., Santhosh, R. and Murugan, A. Incidence and patterns of maxillofacial trauma a retrospective analysis of 3611 patients an update. Oral Maxillofac. Surg. 20, 377 - 383 (2016).

2. Singaram, M., G, S. V. and Udhayakumar, R. K. Prevalence, pattern, etiology, and management of maxillofacial trauma in a developing country: a retrospective study. J. Korean Assoc. Oral Maxillofac. Surg. 42, $174-181$ (2016).

3. Tiwana, P. S., Kushner, G. M. and Alpert, B. Lag screw fixation of anterior mandibular fractures: a retrospective analysis of intraoperative and postoperative complications. J. oral Maxillofac. Surg. Off. J. Am. Assoc. Oral Maxillofac. Surg. 65, $1180-1185$ (2007).

4. Al-Moraissi, E. A. and Ellis, E. Surgical Management of Anterior Mandibular Fractures: A Systematic Review and Meta-Analysis. J. Oral Maxillofac. Surg. 72, 2507.e1 - 2507.e11 (2014).

5. Ellis, E. $3^{\text {rd }}$. Treatment methods for fractures of the mandibular angle. Int. J. Oral Maxillofac. Surg. 28, $243-252$ (1999).

6. Höfer, S. H., Ha, L., Ballon, A., Sader, R. and Landes, C. Treatment of mandibular angle fractures - linea obliqua plate versus grid plate. J. cranio-maxillo-facial Surg. Off. Publ. Eur. Assoc. Cranio-Maxillo-Facial Surg. 40, 807 - 811 (2012).

7. Gear, A. J. L., Apasova, E., Schmitz, J. P. and Schubert, W. Treatment modalities for mandibular angle fractures. J. oral Maxillofac. Surg. Off. J. Am. Assoc. Oral Maxillofac. Surg. 63, $655-663$ (2005).

8. Wusiman, P., Taxifulati, D., Weidong, L. and Moming, A. Three-dimensional versus standard miniplate, lag screws versus miniplates, locking plate versus non locking miniplates: Management of mandibular fractures, a systematic review and meta-analysis. J. Dent. Sci. 14, 66 - 80 (2019).

9. Sauerbier, S., Schön, R., Otten, J.-E., Schmelzeisen, R. and Gutwald, R. The development of plate osteosynthesis for the treatment of fractures of the mandibular body - a literature review. J. cranio-maxillo-facial Surg. Off. Publ. Eur. Assoc. Cranio-Maxillo-Facial Surg. 36, 251 - 259 (2008).

10. García Carricondo, A. R., Quesada Bravo, F. J., Espín Gálvez, F., Parrón Carreño, T. and Alarcón Rodriguez, R. A comparative study between traditional fixation with miniplates and modified lag screws for the treatment of mandibular fractures. Clin. Oral Investig. 22, $1503-1511$ (2018).

11. Richardson, M., Hayes, J., Jordan, J. R., Puckett, A. and Fort, M. Biomechanical Evaluation of a Mandibular Spanning Plate Technique Compared to Standard Plating Techniques to Treat Mandibular Symphyseal Fractures. Surg. Res. Pract. 2015, 569030 (2015).

12. Sugiura, T., Yamamoto, K., Murakami, K and Sugimura, M. A comparative evaluation of osteosynthesis with lag screws, miniplates or Kirschner wires for mandibular condylar process fractures. J. oral Maxillofac. Surg. Off. J. Am. Assoc. Oral Maxillofac. Surg. 59, $1161-1170$ (2001).

13. Moher, D. et al. CONSORT 2010 explanation and elaboration: Updated guidelines for reporting parallel group randomised trials. Int. J. Surg. (2012). doi:10.1016/j.ijsu.2011.10.001.

14. Jadwani, S. and Bansod, S. Lag Screw Fixation of Fracture of the Anterior Mandible: A New Minimal Access Technique. J. Maxillofac. Oral Surg. 10, $176-180$ (2011).

15. Feller, K. U., Richter, G., Schneider, M. and Eckelt, U. Combination of microplate and miniplate for osteosynthesis of mandibular fractures: An experimental study. Int. J. Oral Maxillofac. Surg. 31, $78-83$ (2002).

16. Vashistha, A., Singh, M., Chaudhary, M., Agarwal, $\mathrm{N}$. and Kaur, G. Comparison of $2 \mathrm{~mm}$ single locking miniplates versus $2 \mathrm{~mm}$ two non locking miniplates in symphysis and parasymphysis fracture of mandible. J. Oral Biol. Craniofacial Res. 7, $42-48$ (2017).

17. Yazdani, J., Ghavimi, M., Taghizadeh, M., Kananizadeh, Y. and Ghanizadeh, M. Effectiveness of placement of second miniplates as tension band unit in mandibular parasymphysis fractures. Dent. Res. J. (Isfahan). 16, $172-178$ (2019).

18. Prasad, R., Thangavelu, K. and John, R. The role of $3 \mathrm{D}$ plating system in mandibular fractures: A prospective study. Journal of Pharmacy and Bioallied Sciences 5, S10 (2013).

19. Elhussein, M. S., Sharara, A. A. and Ragab, H. R. A COMPARATIVE STUDY OF CORTICAL LAG SCREWS AND MINIPLATES FOR INTERNAL 
FIXATION OF MANDIBULAR SYMPHYSEAL REGION FRACTURES. Alexandria Dent. J. 42, 1 - 6 (2017).

20. El Nakeeb, N. A., El Dibany, M. M. and Shokry, M. M. A COMPARATIVE STUDY BETWEEN 3-D PLATES AND CONVENTIONAL MINIPLATES FOR INTERNAL FIXATION OF ANTERIOR MANDIBULAR FRACTURES. Alexandria Dent. J. 41, 253 - 260 (2016).

21. Tiwari, M., Meshram, V., Lambade, P. and Fernandes, G. Titanium Lag Screw Versus Miniplate Fixation in the Treatment of Anterior Mandibular Fractures. J. Oral Maxillofac. Surg. 77, $1031-1039$ (2019).

22. Schaaf, H. et al. Comparison of miniplate versus lag-screw osteosynthesis for fractures of the mandibular angle. Oral Surgery, Oral Med. Oral Pathol. Oral Radiol. Endodontology 111, 34 - 40 (2011).

23. Cheng, H. et al. Prolonged operative duration is associated with complications: a systematic review and meta-analysis. Journal of Surgical Research 229, 134 - 144 (2018).

24. Goyal, M. et al. A Comparative Evaluation of Fixation Techniques in Anterior Mandibular Fractures Using $2.0 \mathrm{~mm}$ Monocortical Titanium Miniplates Versus $2.4 \mathrm{~mm}$ Cortical Titanium Lag Screws. J. Maxillofac. Oral Surg. 11, $442-450$ (2012).

25. Bhatnagar, A., Bansal, V., Kumar, S. and Mowar, A. Comparative Analysis of Osteosynthesis of Mandibular Anterior Fractures Following Open Reduction Using 'Stainless Steel Lag Screws and Mini Plates'. J. Maxillofac. Oral Surg. 12, $133-139$ (2013).

26. Agnihotri, A., Prabhu, S. and Thomas, S. A comparative analysis of the efficacy of cortical screws as lag screws and miniplates for internal fixation of mandibular symphyseal region fractures: A randomized prospective study. Int. J. Oral Maxillofac. Surg. 43, 22 - 28 (2014). 